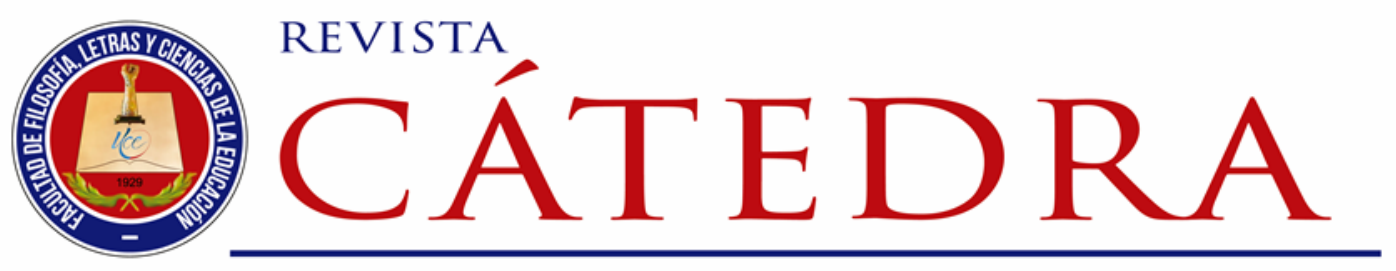

\title{
Apropiación del Capital Tecnológico de los docentes durante la pandemia de Covid-19
}

\section{Teachers' Appropriation of Technological Capital during the Covid-19 pandemic}

\author{
Lizbeth Ponce-Tituaña \\ Universidad Andina Simón Bolívar, Quito, Ecuador \\ lizbeth.ponce@uasb.edu.ec \\ https://orcid.org/0000-0002-9126-4866
}

Alex Lucio-Paredes

Universidad Central del Ecuador, Quito, Ecuador

aolucio@uce.edu.ec

https://orcid.org/0000-0002-1033-2688

(Recibido: 17/03/2021; Aceptado: 23/03/2021; Versión final recibida: 28/04/2021)

Cita del artículo: Ponce-Tituaña, L. y Lucio-Paredes, A. (2021). Apropiación del Capital Tecnológico de los docentes durante la pandemia de Covid-19. Revista Cátedra. 4(2),18-38.

\section{Resumen}

La pandemia de Covid-19 provocó la suspensión de clases presenciales. Los limitados recursos y capacidades del país para generar procesos de educación no presencial, la desigualdad educativa y la brecha digital, marcó desafíos para dar continuidad a la educación utilizando las TIC. El estudio tuvo como objetivo analizar las formas y niveles de apropiación de Capital Tecnológico en su estado: objetivado, incorporado e institucionalizado y su aplicación en el proceso de enseñanza-aprendizaje.

La investigación es de enfoque cuantitativo y se realizó en las Unidades Educativas: Abdón Calderón, Alto Cenepa y Rafael Alvarado (Quito-Ecuador) desde septiembre de 2020 a enero de 2021. El método de recolección de datos fue la encuesta. El cuestionario de 38 preguntas se aplicó a 109 docentes. Los resultados demostraron que la media del capital tecnológico incorporado de los docentes es 11,1 \% Avanzado, 20,4 \% Intermedio, 21,8 \% Medio, 27,1 \% Básico, y un 13,1 \% Nulo. En los últimos 6 meses previos al estudio, el $72 \%$ de docentes recibió un certificado de capacitación sobre competencias digitales. Las formas dominantes de capital objetivado son laptop y smartphone. El 35,8 \% de 10 a 20 megabytes, el 34,9\% de 1.5 a 5 megabytes y el $22,9 \%$ de 30 a 40 megabytes en la velocidad de internet.

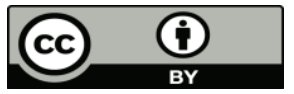


La educación es una responsabilidad del Estado, y debe destinar los recursos necesarios para dotar a los docentes de herramientas tecnológicas, capacitarlos y certificarlos en el uso de las TIC de forma gratuita, permanente y oportuna.

\section{Palabras clave}

Apropiación, capital tecnológico, competencias, incorporado, institucionalizado, objetivado.

\section{Abstract}

The Covid-19 pandemic led to the suspension of face-to-face classes. The country's limited resources and capacities to generate non-face-to-face education processes, educational inequality and the digital divide posed challenges to the continuity of education using ICTs. The objective of the study was to analyze the forms and levels of appropriation of technological capital in its state: objectified, incorporated and institutionalized, and its application in the teaching-learning process.

The research has a quantitative approach and was conducted in the Educational Units: Abdón Calderón, Alto Cenepa and Rafael Alvarado (Quito-Ecuador) from September 2020 to January 2021. The data collection method was the survey. The 38-question questionnaire was applied to 109 teachers. The results showed that the mean of teachers' embodied technological capital is $11.1 \%$ Advanced, $20.4 \%$ Intermediate, $21.8 \%$ Medium, $27.1 \%$ Basic and $13.1 \%$ Null. In the last 6 months prior to the study, $72 \%$ of teachers received a training certificate on digital competencies. The dominant forms of objectified capital are laptop and smartphone. $35.8 \%$ from 10 to 20 megabytes, $34.9 \%$ from 1.5 to 5 megabytes and $22.9 \%$ from 30 to 40 megabytes of internet speed.

Education is a responsibility of the State and it must allocate the necessary resources to provide teachers with technological tools, train them and certify them in the use of ICTs free of charge, permanently and in a timely manner.

\section{Keywords}

Appropriation, technological capital, competencies, embedded, institutionalized, objectified.

\section{Introducción}

La Organización Mundial de la Salud -OMS—, declaró en marzo de 2020 a la Covid-19 como pandemia. Esto provocó la suspensión de las clases presenciales y marcó desafíos para dar continuidad a los aprendizajes. Según la ONU (2020) "los cierres de escuelas y otros centros de enseñanza han afectado al $94 \%$ de los estudiantes de todo el mundo" (pág. 2). La pandemia agudizó la desigualdad para acceder al sistema educativo. Para esta organización internacional el $40 \%$ de los países más pobres, no han logrado ejecutar políticas públicas eficaces que logren garantizar el derecho a la educación durante la crisis sanitaria. Los estudiantes y los docentes más afectados, son aquellos en situación de vulnerabilidad, entre los cuales, se encuentran los que tienen "menos competencias digitales y un menor acceso a la conectividad y el equipo informático" (ONU, 2020, pág. 8).

Para dar continuidad a la educación a través de medios no presenciales, según la CEPALUNESCO (2020) "requiere tomar en cuenta las características de los currículos nacionales (...), los recursos y capacidades del país para generar procesos de educación a distancia, los niveles de segregación y desigualdad educativa del país" (pág. 3). En Ecuador, según la Encuesta Multipropósito, referente a las TIC, arrojó los siguientes resultados a nivel 
nacional; solo el 45,5 \% de hogares tiene acceso a internet y solo el 23,3 \% a nivel nacional utiliza una computadora de escritorio en sus hogares. La red social más usada es WhatsApp, sin embargo, solo el 24,3 \% del quintil de ingresos económicos uno la usa (INEC, 2019, pág. 1-40). Según la CEPAL-UNESCO (2020) de 33 países analizados solo 14 países consideraron necesaria "la capacitación de docentes, especialmente en herramientas para el uso y manejo de las tecnologías de la información y comunicación (TIC)” (pág. 3). Este estudio afirmó que la capacitación en uso y aplicación de TIC a los docentes en Ecuador, tuvo grandes limitaciones, simplificando la formación docente a la mera ejecución de un curso de autoaprendizaje denominado Mi Aula en Línea.

La aplicación que hagan los docentes de las TIC, en el proceso de enseñanza, posibilita variaciones en los resultados del aprendizaje, según Botello y Guerrero (2014), "el uso conjunto de las TIC permite incrementar el puntaje promedio de los estudiantes en la prueba PISA entre un $5 \%$ y un 6 \% (...) cuando las TIC se utilizan dentro del aula" (pág. 10).

En este escenario, las TIC y el conocimiento sobre ellas, se convierte en una nueva especie de Capital Cultural que se ha denominado como Capital Tecnológico. Según Ramírez y Casillas (2014) desde la perspectiva de Pierre Bourdieu afirman que:

El capital tecnológico (kt) comprende al conjunto de saberes, savoir-faire y saber usar en su proceso de aprendizaje (...). Su posesión es un atributo que diferencia a los individuos y les permite competir de mejor manera en muy diversos campos y espacios sociales (pág. 14).

Por tal razón, resulta importante analizar la apropiación del Capital Tecnológico de los docentes y su aplicación en el proceso de enseñanza-aprendizaje, para evidenciar los desafíos que afronta el sistema educativo en medio de una pandemia, que ha profundizado las dificultades ya existentes y ha creado otras en la educación.

El contenido del artículo es un estudio al Capital Tecnológico de los docentes que laboran en la Unidad Educativa Abdón Calderón, institución pública; la Unidad Educativa Alto Cenepa, institución particular, y la Unidad Educativa Rafael Alvarado, institución municipal del Distrito Metropolitano de Quito, Ecuador, desde septiembre de 2020 a enero de 2021. El estudio permitió analizar las formas y niveles de apropiación de Capital Tecnológico en su estado: objetivado, incorporado, e institucionalizado por parte de los docentes, y su aplicación en el proceso de enseñanza-aprendizaje.

Los obstáculos del estudio fueron las limitaciones legales y fácticas en la aplicación del instrumento. Existe desconfianza en los encuestados al responder interrogantes referentes a su espacio de trabajo. Los motivos son diferentes, pero, principalmente, desconfianza a represalias por la visibilización de la falta de capacitación, implementación y dotación en cuanto al capital tecnológico.

La estructura del artículo se compone de la introducción, donde se formula y justifica el problema de la investigación, el objeto, objetivos, y limitaciones presentadas durante el estudio. Asimismo, se establece la contribución del artículo a la educación. En la revisión de la literatura, se desarrolla el concepto de Capital Tecnológico, detallando el estado objetivado, incorporado e institucionalizado. Finalizamos con la exposición de los datos estadísticos, la discusión de resultados, y presentamos las conclusiones de la investigación.

\section{Revisión de literatura}

El inicio del siglo XXI está marcado por el desarrollo explosivo de las Tecnologías de la Información y Comunicación (UNESCO, 2013, pág. 10). Tanto así, que la sociedad se ha 
transformado en un panóptico digital, donde "internet, smartphone, y las Google glass, (...) domina la apariencia de la libertad y la comunicación ilimitada” (Han, 2014, pág. 33). Por otra parte, Castells afirma que estamos en una sociedad red "cuya estructura social está compuesta por redes activadas de tecnologías digitales de la comunicación y de la información basadas en la microelectrónica" (Castells, 2009, pág. 49). Como muestra, en el 2017 en "Ecuador el 80 \% de los jóvenes entre los 18 a 24 años usan internet" (UNESCO, 2017, pág. 11). Aunque "ello no significa, (...) que las personas de todo el mundo participen en las redes. De hecho, por ahora, la mayoría no lo hace" (Castells, 2009, pág. 51). Por ejemplo, en el país solo el $38 \%$ del quintil uno de ingresos accede a una red de internet (UNESCO, 2017, pág.10), por razones de situación geográfica o condición socio-económica.

En el marco de la sociedad red, la teoría pedagógica del conectivismo concibe a la educación como un proceso de "transmitir y estimular (...) recursos a través de la utilización de herramientas tecnológicas, generando un producto más rápido y eficiente" (Krüger, 2006, párr. 17). Sin embargo, la educación "no se trata únicamente del uso de dispositivos. Detrás de un aparato y de una plataforma está un conjunto de factores que dan sentido a su uso (...)" (Mendoza, 2020, pág. 347).

Durante la pandemia los actores educativos han aplicado con mayor frecuencia las tecnologías en la enseñanza porque “(...) favorecen el contacto no presencial entre las personas y el hallazgo de conocimientos (...)” (Uzcátegui y Albarrán, 2020, pág. 44). Aunque este proceso no es mecánico, porque,

las tecnologías inteligentes como Internet no pueden considerarse simples vehículos que transportan la información, sino que, al ampliar y complejizar el proceso de acceso, procesamiento y expresión del conocimiento, modifican sustancialmente la manera en la que el individuo se construye a sí mismo, comprende el contexto y se comprende a sí mismo (Pérez, 2013, pág. 55).

\subsection{Capital tecnológico (KT)}

El Capital Cultural está constituido por "factores culturales de clase y los factores económicos" (Bourdieu, 2003, pág. 33). Por lo tanto, para Bourdieu esto significa "una ruptura con los supuestos inherentes tanto a la visión común que considera el éxito o el fracaso escolar como el resultado de las aptitudes naturales" (Bourdieu, 2012, pág. 11). En el marco de la sociedad red, desde la perspectiva del Capital Cultural, se ha desarrollado el concepto de Capital Tecnológico, que permite,

comprender cómo se constituye la práctica en el uso de tecnología digital en el acontecer de los individuos, dentro de un marco institucional, (...) siendo, como indican los roles, metas, representaciones sociales y habitus de los agentes involucrados, los que finalmente generarán o no, una transformación en el proceso educativo mediado por TIC (Salado, Velázquez y Ochoa, 2014, pág. 217).

El Capital Tecnológico está constituido y representado en los estados: objetivado, incorporado e institucionalizado.

\subsection{Capital tecnológico objetivado}

En su estado objetivado, el Capital Tecnológico es el,

conjunto de objetos tecnológicos que son apropiados en su materialidad y en su significado simbólico. Dispositivos tecnológicos, recursos de 
conectividad, software (original/pirata), grado de actualización (versión) y se observa mediante el equipamiento, la conectividad y el gasto o la inversión en (...) insumos de tecnología (Salado-Rodríguez y Ramírez-Martinell, 2018, pág. 129).

En el proceso educativo, el capital objetivado es importante porque, por ejemplo; "mientras que en un aula el profesor tiene la inmediatez de la comunicación con sus alumnos, en un evento a distancia la interacción depende de conexiones, velocidad de transmisión de datos, video y audio de calidad" (Mendoza, 2020, pág. 348) y otros factores que inciden en el desempeño laboral.

\subsection{Capital tecnológico incorporado}

En su estado incorporado, el Capital Tecnológico está constituido "por los saberes (...): dominio sobre paquetería y programas, así como otras habilidades relacionadas con las TIC" (Salado-Rodríguez y Ramírez-Martinell, 2018, pág. 130). Sin embargo, esta definición bajo las condiciones de la sociedad red, resulta incompleta e insuficiente, por su excesiva generalidad y ambigüedad que no permite tener certeza de cuáles son aquellas habilidades específicas que los docentes han de conocer y aplicar en el proceso de enseñanza.

Para complementar el estado incorporado del Capital Tecnológico y brindar certeza sobre aquellos conocimientos que el docente deberá aprehender en cuanto a las TIC, nos referimos al concepto de competencia digital; que consiste en "aptitudes, conocimientos (...) para crear y manejar información (...) y capacidad para usar las TIC, que son herramientas primordiales para el manejo de la información" (UNESCO, 2019, pág. 60).

Según el organismo especializado de las Naciones Unidas los docentes deben incorporar seis aspectos del Capital Tecnológico en su práctica profesional, que son: "1. Comprensión del papel de las TIC en las políticas educativas; 2 . Currículo y evaluación; 3. Pedagogía; 4. Aplicación de competencias digitales; 5. Organización y administración; 6. Aprendizaje profesional de los docentes" (UNESCO, 2019, pág. 10), con la finalidad de desarrollar el proceso de enseñanza-aprendizaje y potenciar su propio desarrollo profesional.

\section{Capital tecnológico incorporado}

\section{Aspectos \\ Competencia de los Docentes}

Comprensión del papel de las TIC en las políticas educativas

Currículo y evaluación

Pedagogía

Aplicación de competencias digitales
Determinar cómo y en qué medida sus prácticas docentes corresponden con las políticas institucionales $\mathrm{y} / \mathrm{o}$ nacionales $\mathrm{y}$ apoyan $\mathrm{su}$ consecución.

Analizar las normas curriculares y determinar el posible uso pedagógico de las TIC para cumplir dichas normas.

Seleccionar adecuadamente las TIC en apoyo a metodologías específicas de enseñanza y aprendizaje.

Conocer las funciones de los componentes de equipos informáticos y los programas de productividad más comunes, y ser capaz de utilizarlos. 
Organización y administración Organizar el entorno físico, de tal manera, que la tecnología esté al servicio de distintas metodologías de aprendizaje de forma inclusiva.

Aprendizaje profesional de los Utilizar las TIC para su propio perfeccionamiento docentes profesional.

Cuadro 1. Aspectos y competencias digitales del Capital tecnológico incorporado (UNESCO, 2019, pág. 28-33)

\subsection{Capital tecnológico institucionalizado}

En su estado institucionalizado el Capital Tecnológico está constituido por el,

conjunto de títulos, diplomas y certificados que validan, instituyen y reconocen saberes, conocimientos y habilidades que recubren de un valor simbólico al diploma (factor institución, grado de prestigio) y define un status jerárquico por el tipo de conocimiento y se mide en términos del número de cursos y diplomas y certificados (Casillas, Ramírez y Ortiz, 2013, pág. 7).

El Capital Tecnológico institucionalizado cumple la función de ser "percibido por agentes sociales cuyas categorías de percepción son tales que están en capacidad de conocerlo (percibirlo) y reconocerlo, otorgarlo valor" (Bourdieu, 2001, pág. 116), en medio de una sociedad red, donde el uso de las TIC según Vein "están influyendo en el empleo tanto por tratarse de una industria que crea puestos de trabajo como por ser una herramienta que permite a los trabajadores acceder a nuevas formas laborales, de una manera novedosa y más flexible" (2003, párr. 8).

\section{Metodología}

La investigación se basó en el enfoque cuantitativo. El método de recolección de datos fue la encuesta y el instrumento el cuestionario. A continuación, se detalla el proceso que se siguió para la obtención de los datos:

1. Selección del área de investigación: La pandemia, la restricción parcial de la movilidad, y la enseñanza no presencial, fueron limitaciones para el área de estudio seleccionado. La investigación se llevó a cabo en las instituciones educativas que nos brindaron las facilidades y permisos para poder realizarla. Las áreas seleccionadas fueron la Unidad Educativa Abdón Calderón, institución pública, ubicada en la parroquia de Calderón; la Unidad Educativa Alto Cenepa, institución particular, ubicada en la parroquia de Calderón; la Unidad Educativa Municipal Rafael Alvarado, institución municipal, ubicada en la parroquia de Tumbaco.

2. Población: Se trabajó con el universo de docentes de las tres instituciones educativas. El total de la población fue de 109 docentes, sus edades van desde los 20 años y superan los 60 años. La población de docentes de la Unidad Educativa Abdón Calderón fue de 69 docentes; Unidad Educativa Municipal Rafael Alvarado fue de 24 docentes, y la Unidad Educativa Particular Alto Cenepa fue de 16 docentes.

3. Diseño y aplicación de los instrumentos de investigación: El instrumento aplicado para la recolección de datos, fue el cuestionario elaborado en la herramienta Microsoft Forms de Microsoft Office 365. Se lo realizó en esta aplicación por motivos de seguridad y de fácil acceso, al mismo tiempo, es de conocimiento general para los docentes, porque el Ministerio de Educación dotó de cuentas institucionales de Office a todos los docentes del sector público, además, los 
educadores de las demás instituciones también manejan correos institucionales, por tal motivo, la herramienta no fue nueva para ellos.

4. Validación del instrumento: Para determinar la legitimidad, se solicitó la validación del cuestionario de tres expertos: un docente de la Universidad Andina Simón Bolívar; otro docente de la Universidad Central del Ecuador y un docente que pertenece al Ministerio de Educación.

5. Análisis de datos: los datos obtenidos fueron interpretados haciendo uso de Microsoft Excel. Se unificaron los datos de las tres instituciones educativas con el fin de realizar un análisis a profundidad sobre el Capital Tecnológico, objetivado, incorporado e institucionalizado.

\subsection{Cuestionario de análisis sobre el Capital Tecnológico a los docentes}

El cuestionario que se aplicó a los docentes de instituciones educativas; público, particular y municipal consta de treinta y ocho preguntas. De la pregunta uno a la pregunta cuatro, se indaga sobre los datos informativos de los docentes; de la pregunta cinco a la pregunta treinta y ocho se hace una exploración sobre los tres estados que comprende el capital tecnológico, que a continuación detallamos:

De la pregunta cinco a la veinte y ocho, se indaga sobre el capital tecnológico objetivado; desde la pregunta veinte y nueve hasta la pregunta treinta y tres, se indaga sobre el capital tecnológico incorporado; finalmente, desde la pregunta treinta y cuatro hasta la treinta y ocho, se indaga sobre el capital tecnológico institucionalizado.

\subsection{Confiabilidad del cuestionario tipo Likert (politómica ordinal)}

Para determinar la confiabilidad del cuestionario, calculamos el alfa de Cronbach $(\propto)$, que "describen o explican el significado de la estadística alfa de varias formas" (Taber, 2017, pág. 3). Además, es una medida de fiabilidad de las encuestas realizadas en estudios de investigación científica en educación. La fórmula para el cálculo del alfa de Cronbach se encuentra en la Ecuación 1, y es la siguiente:

$$
\propto=\frac{K}{K-1}\left[1-\frac{\sum_{\mathrm{i}_{=1}}^{\mathrm{k}} \sigma_{\mathrm{Yi}}^{2}}{\sigma_{\mathrm{X}}^{2}}\right]
$$

Ecuación 1

$\propto=$ Alpha de Cronbanch.

$\mathrm{K}=$ Cantidad de preguntas. En esta investigación, tres se aplicaron con escala de Likert, con un total de 45 ítems, cada una con una escala de cinco opciones.

$\sigma_{Y i}^{2}=$ Varianza de las puntuaciones de la pregunta i.

$\sigma_{X}^{2}=$ Varianza de las puntuaciones observadas de los individuos. En nuestra investigación, las 109 respuestas de las encuestas.

El cálculo del alpha de Cronbanch $(\propto)$ fue de 1, esto nos permite tener un alto grado de confiabilidad del cuestionario utilizado para conocer las competencias digitales de los docentes, en referencia al Capital Tecnológico incorporado.

\subsection{Recolección de datos}

Treinta y cuatro preguntas del cuestionario son de opción múltiple. Tres preguntas han sido elaboradas bajo la escala de Likert (cualitativa politómica ordinal) correspondiente a una 
escala de percepción de habilidades (avanzado, intermedio, medio, básico y nulo); una pregunta ha sido estructurada bajo la escala de Likert (cuantitativa dicotómica) con la opción de sí y no.

La encuesta se llevó a cabo durante el primer quimestre del año escolar del Régimen Sierra en la Unidad Educativa Abdón Calderón (Pública-Calderón), Unidad Educativa Municipal Rafael Alvarado (Municipal- Tumbaco) y la Unidad Educativa Particular Alto Cenepa (Particular- Calderón).

\subsection{Población}

La realización del cuestionario fue de carácter voluntario (los docentes fueron notificados por las autoridades de las instituciones sobre esta investigación a sus correos electrónicos institucionales, aclarando que la realización era de manera libre y voluntaria) el enlace de la encuesta de Microsoft Forms fue enviado a los correos institucionales de las autoridades principales de las instituciones educativas. El total de los docentes encuestados de las tres instituciones fue de 109, entre hombres y mujeres.

\section{Metodología}

\subsection{Recolección de datos}

En el estudio participaron un total de 109 docentes, cada uno con los siguientes datos informativos:

\begin{tabular}{lccrr}
\hline & U.E. A. C & U.E.M R. A & U.E. P. A. & $\%$ \\
& & & C & \\
\hline Género & 45 & 21 & 8 & 68 \\
Femenino & 24 & 3 & 8 & 32,1 \\
Masculino & 0 & 0 & 0 & 0,0 \\
Otro & 69 & 24 & 16 & 100,0 \\
Total & & & & \\
Rango de edad & 4 & 0 & 3 & 6,4 \\
Entre 20 a 30 años & 20 & 7 & 7 & 31,2 \\
Entre 31 a 40 años & 22 & 11 & 4 & 33,9 \\
Entre 41 a 50 años & 21 & 5 & 1 & 24,8 \\
Entre 51 a 60 años & 2 & 1 & 1 & 3,7 \\
Entre 60 años y más & 69 & 24 & 16 & 100,0 \\
Total & & & & \\
Nivel que imparte clases & & & & \\
Inicial I y II & 0 & 0 & 0 & 0,0 \\
Preparatoria & 0 & 0 & 2 & 1,8 \\
Educación General Básica Elemental & 0 & 0 & 2 & 1,8 \\
Educación General Básica Media & 0 & 2 & 2 & 3,7 \\
Educación General Básica Superior & 30 & 11 & 5 & 42,2 \\
Bachillerato & 39 & 11 & 5 & 50,5 \\
Total & 69 & 24 & 16 & 100,0 \\
\hline
\end{tabular}




\begin{tabular}{lcccr}
\hline Nivel de ingresos económicos & & & & \\
& 7 & 2 & 1 & 9,2 \\
Inferior a 400 & 11 & 0 & 7 & 16,5 \\
De 401 a 600 & 23 & 5 & 2 & 27,5 \\
De 601 a 800 & 22 & 11 & 2 & 32,1 \\
De 801 a 1000 & 6 & 6 & 4 & 14,7 \\
Más de 1000 & 69 & 24 & 16 & 100,0 \\
Total &
\end{tabular}

Cuadro 2. Datos informativos de los docentes de las tres instituciones educativas

\subsection{Capital Tecnológico Objetivado}

Los docentes de las tres instituciones educativas en la pregunta 5, sobre los equipos electrónicos que poseen en su casa, se les pidió que seleccionen varias opciones. Las tres opciones con mayor elección fueron una laptop, impresora con escáner y radio. En la pregunta 6 los docentes respondieron que el 89,9\% disponen de internet de banda ancha 0 fibra óptica, el otro 7,3 \% su acceso a internet es de un vecino o familiar cercano y el 1,8 \% su acceso es por recargas telefónicas. En la pregunta 7 sobre el tipo de velocidad de su internet el $34,9 \%$ respondieron que tienen de 1.5 a 5 mbps, el $35,8 \%$ de 10 a $20 \mathrm{mbps}$, el $22,9 \%$ de 30 a 40 mbps, el 5,5\% de 80 a 100 mbps y el $0.9 \% 200$ mbps y más. En la pregunta 8 de ¿Cuánto tiempo emplea el uso de internet para distracción personal o navegar en redes sociales? El $68 \%$ respondió de 30 minutos a 1 hora, el 21,1\% de 2 a 3 horas, 6,4 \% de 4 a 6 horas y el 4,6 \% más de 6 horas. En la siguiente pregunta sobre ¿qué tipos de redes sociales frecuentan para su distracción? Entre las tres principales se encuentra Facebook, WhatsApp y YouTube.

La pregunta 10 que hace referencia a ¿cuánto tiempo emplea para planificar sus clases?, el $10,1 \%$ de 30 minutos a 1 hora, el $50 \%$ de 2 a 3 horas, el 19,3\% de 4 a 6 horas y el 20,2\% más de 6 horas. En la pregunta 11 sobre ¿Cuánto tiempo emplea para impartir clases a sus estudiantes mediante el uso de las plataformas digitales? El 39,4 \% de 40 minutos a 1 hora, el $12,8 \% 1$ hora, el $47,7 \%$ de 4 a 6 horas. En la pregunta 12 sobre $¿ Q u e ́$ plataformas digitales utiliza usted para impartir clases en sus asignaturas? 101 docentes respondieron que la plataforma más usada es Zoom Meeting. Sobre la pregunta 13 de ¿Qué tipo de herramientas digitales utiliza usted para impartir sus clases? Respondieron que, el 94,5\% usan herramientas sincrónicas y el 5,5 \% herramientas asincrónicas. En la pregunta 14 sobre ¿Qué tipo de recursos digitales utiliza usted para planificar sus clases?, 89 docentes usan plataformas educativas, 59 docentes usan recursos de gamificación y 49 docentes sobre evaluaciones en línea. La pregunta 15 que señala ¿Qué tipos de plataformas educativas usa usted para asignar las tareas a sus estudiantes? Respondieron el $39 \%$ Google Classroom, el $22 \%$ Moodle, el $19 \%$ Paquete de Microsoft Office 365, el $15 \%$ Plataforma propia de la institución y el $6 \%$ Edmodo. A continuación, en la pregunta 16 se interroga ¿Qué tipos de plataformas educativas usa usted para aplicar las evaluaciones a sus estudiantes? El $35 \%$ respondió que usa Google Classroom, el $22 \%$ Moodle, el $20 \%$ plataforma propia de la institución, el 17 \% usa el Paquete de Microsoft Office 365 y el $6 \%$ Edmodo.

A partir de la pregunta 17 se interroga sobre los equipos tecnológicos que emplea el docente para impartir sus horas de clase. Aquí se pregunta sobre si conoce el docente que las plataformas educativas (creación de entornos virtuales de aprendizaje -EVA - como MOODLE, FirtsClass o creación propia) que usa en el proceso de enseñanza-aprendizaje, tienen licencia. El 68 \% respondió que era gratuita, el 17 \% pagada por la institución y el 16 $\%$ pagada por el docente. En la pregunta 18 se indaga sobre si el docente conoce si la institución donde labora cuenta con una plataforma educativa propia, el $58 \%$ respondió 
que No, el 26 \% dijo que Sí y el 17 \% que desconoce. En la pregunta 19 trata sobre ¿Cuál es el medio que usted usa para impartir sus clases virtuales? El 89 \% respondió que la Laptop, el $10,1 \%$ usa la computadora de escritorio y el 0,9 \% una Tableta. La pregunta 20 es sobre ¿El equipo tecnológico que emplea en sus clases es? Y los docentes respondieron el $59 \%$ una computadora de escritorio, el $18 \%$ una laptop, el $14 \%$ una tableta y el $9 \%$ el smartphone. En la pregunta 21 se interroga sobre si ¿El equipo tecnológico que usted usa para impartir sus clases en línea fue proporcionado por la institución educativa donde labora? El 57 \% de docentes respondió que Sí y el 43 \% respondió que No. En la pregunta 22 ¿El servicio de internet que usa para impartir las clases en línea a sus estudiantes es financiada por la institución educativa donde labora? El $99 \%$ de los docentes respondió que No y el $1 \%$ que Sí.

Desde la pregunta 23 se cuestiona sobre especificaciones tecnológicas de los equipos electrónicos $i$ En sus equipos electrónicos como computadora de escritorio o laptop, qué sistema operativo tiene instalado? El 99,1 \% respondió que el sistema operativo es Windows y el 0,9\% Mac Os. En la pregunta 24 en sus equipos electrónicos como smartphone, ¿Qué sistema operativo tiene instalado? Respondieron el $92 \%$ que el sistema operativo de su smartphone es Android y el $8 \%$ tiene instalado iOS (de la marca Apple). En la pregunta 25 se consulta sobre si los programas (ej. Word, Excel, Power Point y Antivirus) que tiene instalado en sus equipos electrónicos como, computador personal o laptop tienen licencia, sin licencia o desconoce. El $34 \%$ que tiene licencia, el $33 \%$ sin licencia y el otro $33 \%$ que desconoce. En la pregunta 26 se indagó sobre ¿Cuál de los siguientes métodos hace uso para comunicarse con sus amigos y familiares? El $62 \%$ respondió que hace llamadas por vía WhatsApp, el $33 \%$ llamadas celulares directo de su smartphone y el $5 \%$ realiza llamadas telefónicas de un teléfono local de casa. En la pregunta 27 se consulta sobre ¿Cuál de los siguientes medios hace uso para organizar trabajos colaborativos en sus clases? El $76 \%$ respondió que hace uso de reuniones de grupo vía ZOOM, Teams o Skype, el $21 \%$ Chats grupales por WhatsApp, el $2 \%$ Archivos colaborativos en Google Drive y el $1 \%$ Grupos de Facebook. En la pregunta 28 ¿Cuál de los siguientes medios hace uso para coordinar actividades con los representantes legales de sus estudiantes? Respondieron el $52 \%$ chats grupales por WhatsApp, el 43 \% reuniones de grupo vía ZOOM, Teams o Skype y el $5 \%$ correos electrónicos.

\subsection{Capital Tecnológico Incorporado}

Desde la pregunta 29 hasta la pregunta 33 en el cuestionario se preguntó sobre el Capital Tecnológico incorporado.

En la pregunta 29 se indaga sobre si los docentes hacen uso de las siguientes formas para acceder a información académica en las páginas web, a través de una escala de Likert cuantitativa dicotómica compuesta por variables. 


\section{Responda con sí o no, si usted hace uso de las siguientes formas para acceder a} información académica en las páginas web

\begin{tabular}{|c|c|c|c|}
\hline Ítems & Sí \% & No \% & $\begin{array}{l}\text { Total } \\
\%\end{array}$ \\
\hline $\begin{array}{l}\text { Búsqueda avanzada a través de los buscadores como: Google, Bing } \\
\text { Baidu y más. }\end{array}$ & 90,8 & 9,2 & 100 \\
\hline Busca en Google Académico, Redalyc, Dialnet, SciELO y más & 46,8 & 53,2 & 100 \\
\hline $\begin{array}{l}\text { Revisa páginas web especializadas y reconocidas en educación } \\
\text { como: EDUTEKA, EDUCARED, MINEDUC }\end{array}$ & 79,8 & 20,2 & 100 \\
\hline Busca en blogs o páginas web anónimas & 23,9 & 76,1 & 100 \\
\hline $\begin{array}{l}\text { Busca solo en las primeras } 10 \text { páginas que le recomienda su } \\
\text { buscador }\end{array}$ & 43,1 & 56,9 & 100 \\
\hline $\begin{array}{l}\text { Cita en sus archivos académicos las fuentes bibliográficas utilizando } \\
\text { Zotero/Mendeley o las herramientas de Word para citar }\end{array}$ & 53,2 & 46,8 & 100 \\
\hline Reconoce fuentes fiables de información & 78,0 & 22,0 & 100 \\
\hline $\begin{array}{l}\text { Hace uso de páginas web anti plagio para revisar los trabajos } \\
\text { académicos de sus estudiantes }\end{array}$ & 23,9 & 76,1 & 100 \\
\hline $\begin{array}{l}\text { Visita repositorios digitales de universidades o institutos } \\
\text { académicos }\end{array}$ & 55,0 & 45,0 & 100 \\
\hline Utiliza metabuscadores & 26,6 & 73,4 & 100 \\
\hline Busca libros o revistas digitales & 88,1 & 11,9 & 100 \\
\hline
\end{tabular}

Cuadro 3. Usted hace uso de las siguientes formas para acceder a información académica en las páginas web

Como se puede observar en el cuadro 3, los docentes han desarrollado habilidades tecnológicas en la búsqueda y acceso a la información académica en las páginas web. En la búsqueda avanzada a través de los buscadores como: Google, Bing, Baidu y más, respondieron un 90,8 \% Sí y un 9,2 \% No; en referencia a la Búsqueda en Google Académico, Redalyc, Dialnet, SciELO y más el 46,8 \% Sí y un 53,2 \% No; revisa páginas web especializadas y reconocidas en educación como: EDUTEKA, EDUCARED, MINEDUC respondieron que el 79,8 \% Sí y el 20,18 \% No; busca en blogs o páginas web anónimas respondieron el 76,1\% No y el 23,9\% Sí; busca solo en las primeras 10 páginas que le recomienda su buscador el 56,9 \% respondió que No y el 43,1\% Sí; cita en sus archivos académicos las fuentes bibliográficas utilizando Zotero/Mendeley o las herramientas de Word para citar, el 53,2 \% respondió que Sí y el 46,8 \% No; reconoce fuentes fiables de información, el 78 \% respondió que Sí y el 22 \% No; hace uso de páginas web anti plagio para revisar los trabajos académicos de sus estudiantes el 76,1 \% respondió que No y el 23,9 $\%$ Sí; visita repositorios digitales de universidades o institutos académicos el $55 \%$ responde que Sí y el 45 \% No; utiliza metabuscadores el 73,4 \% No y el 26,6 \% Sí; busca libros o revistas digitales el 88,1 \% respondió que Sí y el 11,9 \% que No. Estos datos nos dan un panorama claro sobre cómo los docentes durante el periodo de la pandemia, se han capacitado, sea de forma institucional o personal, para desarrollar habilidades y competencias tecnológicas sobre diversas herramientas, como es el caso del acceso a información en páginas web. 
En la pregunta 30 sobre ¿cuál de los siguientes dispositivos hace mayormente sus búsquedas en páginas web? Respondieron el $78 \%$ en una laptop, $11 \%$ computadora, $10 \%$ smartphone, y el $1 \%$ una tableta. En la pregunta 31 y 32 sobre las competencias digitales que tienen los docentes en el área de la información, alfabetización informacional y el tratamiento de los datos, se obtuvieron los siguientes resultados:

\begin{tabular}{|c|c|c|c|c|c|c|}
\hline & $\begin{array}{c}\text { Pregunta 31: } \\
\text { Competencias digitales I }\end{array}$ & $\begin{array}{c}\text { Avanzado } \\
\%\end{array}$ & $\begin{array}{c}\text { Intermedio } \\
\%\end{array}$ & $\begin{array}{l}\text { Medio } \\
\%\end{array}$ & $\begin{array}{l}\text { Básico } \\
\%\end{array}$ & $\begin{array}{l}\text { Nulo } \\
\%\end{array}$ \\
\hline 1 & $\begin{array}{l}\text { Transferencia de audio, vídeo y } \\
\text { fotografías del dispositivo a la } \\
\text { computadora }\end{array}$ & 14,7 & 24,8 & 33,0 & 24,8 & 2,8 \\
\hline 2 & $\begin{array}{l}\text { Edición de video, audio, imágenes } \\
\text { o mapas bits y de imágenes } \\
\text { vectoriales }\end{array}$ & 7,3 & 14,7 & 22,9 & 36,7 & 18,3 \\
\hline 3 & Conversión de formato de audio & 9,2 & 13,8 & 22,9 & 31,2 & 22,9 \\
\hline 4 & Conversión de formato de vídeo & 10,1 & 16,5 & 20,2 & 34,9 & 18,3 \\
\hline 5 & $\begin{array}{l}\text { Conversión de formato de } \\
\text { imágenes }\end{array}$ & 11,0 & 12,8 & 29,4 & 34,9 & 11,9 \\
\hline 6 & $\begin{array}{l}\text { Escanear y sacar copias a sus } \\
\text { documentos }\end{array}$ & 20,2 & 25,7 & 23,9 & 28,4 & 1,8 \\
\hline 7 & Descargar archivos de páginas web & 21,1 & 29,4 & 29,4 & 18,3 & 1,8 \\
\hline 8 & $\begin{array}{l}\text { Creación de recursos digitales para } \\
\text { exposiciones en clase }\end{array}$ & 13,8 & 27,5 & 35,8 & 22,9 & 0,0 \\
\hline 9 & Uso de plataformas educativas & 12,8 & 30,3 & 33,0 & 22,9 & 0,9 \\
\hline 10 & $\begin{array}{l}\text { Subir archivos a las nubes como } \\
\text { Google Drive o OneDrive }\end{array}$ & 16,5 & 17,4 & 33,0 & 25,7 & 7,3 \\
\hline 11 & $\begin{array}{l}\text { Comprimir y descomprimir } \\
\text { archivos en formato ZIP o RAR }\end{array}$ & 13,8 & 18,3 & 27,5 & 29,4 & 11,0 \\
\hline 12 & $\begin{array}{l}\text { Convertir archivos de Word, } \\
\text { Power Point y Excel a PDF }\end{array}$ & 21,1 & 23,9 & 22,9 & 27,5 & 4,6 \\
\hline 13 & $\begin{array}{l}\text { Subir archivos de Word, PDF o jpg } \\
\text { a las plataformas educativas como } \\
\text { Moodle }\end{array}$ & 11,0 & 28,4 & 24,8 & 24,8 & 11,0 \\
\hline 14 & $\begin{array}{l}\text { Hacer copias de seguridad de sus } \\
\text { cuentas como Whatsapp, fotos y } \\
\text { contactos telefónicos }\end{array}$ & 12,8 & 22,0 & 22,9 & 28,4 & 13,8 \\
\hline 15 & $\begin{array}{l}\text { Organizar reuniones en las } \\
\text { plataformas comunicacionales } \\
\text { como Zoom, Teams, GoToMeeting }\end{array}$ & 15,6 & 27,5 & 27,5 & 19,3 & 10,1 \\
\hline 16 & Realizar compras por internet & 11,9 & 22,9 & 17,4 & 22,0 & 25,7 \\
\hline 17 & Uso de correo electrónico & 22,9 & 26,6 & 13,8 & 22,9 & 13,8 \\
\hline 18 & $\begin{array}{l}\text { Subir vídeos a plataformas como } \\
\text { Youtube }\end{array}$ & 13,8 & 14,7 & 24,8 & 24,8 & 22,0 \\
\hline 19 & $\begin{array}{l}\text { Descargar juegos o programas en } \\
\text { su smartphone sea de Play Store o } \\
\text { App Store }\end{array}$ & 4,6 & 17,4 & 18,3 & 32,1 & 27,5 \\
\hline 20 & $\begin{array}{l}\text { Usar gestores de citas } \\
\text { bibliográficas como: Zotero y } \\
\text { Mendeley }\end{array}$ & 8,3 & 8,3 & 16,5 & 34,9 & 32,1 \\
\hline
\end{tabular}

Cuadro 4. Competencias digitales I 


\begin{tabular}{|c|c|c|c|c|c|c|}
\hline \multicolumn{2}{|r|}{ Pregunta 32: Competencias digitales II } & \multirow{2}{*}{$\begin{array}{c}\begin{array}{c}\text { Avanzado } \\
\%\end{array} \\
11,9\end{array}$} & \multirow{2}{*}{$\begin{array}{c}\begin{array}{c}\text { Intermedio } \\
\%\end{array} \\
24,8\end{array}$} & \multirow{2}{*}{$\begin{array}{l}\text { Medio } \\
\% \\
23,9\end{array}$} & \multirow{2}{*}{$\begin{array}{l}\begin{array}{l}\text { Básico } \\
\%\end{array} \\
21,1\end{array}$} & \multirow{2}{*}{$\begin{array}{l}\begin{array}{l}\text { Nulo } \\
\%\end{array} \\
18,3\end{array}$} \\
\hline 21 & $\begin{array}{l}\text { Usar plataformas educativas (ej. Moodle, } \\
\text { Edmodo, Google Classroom y más) }\end{array}$ & & & & & \\
\hline 22 & Creación de juegos en línea & 4,6 & 11,9 & 17,4 & 24,8 & 41,3 \\
\hline 23 & Diseño de organizadores gráficos en línea & 8,3 & 13,8 & 19,3 & 33,9 & 24,8 \\
\hline 24 & Creación de cursos online -MOOC & 3,7 & 11,9 & 13,8 & 24,8 & 45,9 \\
\hline 25 & Uso de pizarras interactivas & 10,1 & 10,1 & 18,3 & 25,7 & 35,8 \\
\hline 26 & $\begin{array}{l}\text { Creación de instrumentos de evaluación } \\
\text { en línea }\end{array}$ & 8,3 & 21,1 & 20,2 & 33,0 & 17,4 \\
\hline 27 & Diseño de presentaciones interactivas & 9,2 & 17,4 & 26,6 & 33,9 & 12,8 \\
\hline 28 & Diseño de Infografías y diseño gráfico & 6,4 & 15,6 & 18,3 & 36,7 & 22,9 \\
\hline 29 & Videos explicativos animados & 9,2 & 9,2 & 17,4 & 34,9 & 29,4 \\
\hline 30 & Creación de Evaluaciones en línea & 6,4 & 24,8 & 18,3 & 29,4 & 21,1 \\
\hline 31 & Creación de avatares en línea & 2,8 & 11,9 & 17,4 & 29,4 & 38,5 \\
\hline 32 & Diseño de historietas en línea & 3,7 & 11,0 & 16,5 & 22,0 & 46,8 \\
\hline 33 & $\begin{array}{l}\text { Crear foros, asignar tareas, evaluaciones } \\
\text { y subir archivos a plataformas como } \\
\text { Moodle, Edmodo, Google Classroom y } \\
\text { más. }\end{array}$ & 14,7 & 20,2 & 19,3 & 22,0 & 23,9 \\
\hline 34 & $\begin{array}{l}\text { Uso de los recursos de Zoom y Teams } \\
\text { como crear una pizarra digital, la función } \\
\text { de grabar y compartir pantalla }\end{array}$ & 14,7 & 30,3 & 18,3 & 24,8 & 11,9 \\
\hline 35 & Crear gifs y sticker de Whatsapp & 6,4 & 15,6 & 19,3 & 22,0 & 36,7 \\
\hline
\end{tabular}

Cuadro 5. Competencias digitales II

En el caso de las competencias digitales en referencia al área de creación de contenido digital; la comunicación y colaboración de los docentes se pueden observar en el cuadro 4 y 5 , donde se consigue denotar que la escala de competencia predominante es Intermedio y medio, básico y nulo, de los 35 diferentes ítems propuestos en el cuestionario. Durante la pandemia, muchos de los docentes se vieron expuestos a capacitarse en el dominio de varias competencias digitales para poder impartir las clases virtuales a sus estudiantes y continuar con el correcto proceso de enseñanza- aprendizaje.

Para conocer la desviación estándar, la media y el nivel de confianza de las preguntas 31 y 32 , donde se analiza las competencias digitales que poseen los docentes en referencia al capital tecnológico incorporado. En la pregunta 31 y en relación al cuadro 3 sobre las Competencias Digitales I.

\begin{tabular}{lccc}
\hline $\begin{array}{c}\text { Pregunta } \\
31\end{array}$ & Media & $\begin{array}{c}\text { Desviación } \\
\text { estándar }\end{array}$ & $\begin{array}{c}\text { Nivel de } \\
\text { confianza }\end{array}$ \\
\hline Avanzado & 13,6 & 4,9 & 2,29 \\
Intermedio & 21,1 & 6,4 & 3,02 \\
Medio & 25,0 & 6,1 & 2,84 \\
Básico & 27,3 & 5,4 & 2,53 \\
Nulo & 12,9 & 9,6 & 4,51 \\
\hline \multicolumn{2}{c}{ Cuadro 6. Análisis descriptivo, Competencias digitales I }
\end{tabular}


La tendencia estadística sobre la media del nivel de las competencias digitales incorporadas por los docentes, en el nivel de dominio Avanzado tiene una media de 13,6 \%; Intermedio 21,1 \%; Medio 25,0 \%; Básico 27,3 \% y Nulo 12,9 \%.

En la pregunta 32, que tiene relación al cuadro 4 sobre Competencias Digitales II:

\begin{tabular}{lccc}
\hline Pregunta 32 & Media & $\begin{array}{c}\text { Desviación } \\
\text { estándar }\end{array}$ & $\begin{array}{c}\text { Nivel de } \\
\text { confianza }\end{array}$ \\
\hline Avanzado & 8,0 & 3,7 & 2,1 \\
Intermedio & 16,6 & 6,3 & 3,5 \\
Medio & 19,0 & 3,0 & 1,7 \\
Básico & 27,9 & 5,4 & 3,0 \\
Nulo & 28,5 & 11,6 & 6,4 \\
\hline \multicolumn{2}{c}{ Cuadro 7. Análisis descriptivo, Competencias digitales II }
\end{tabular}

La tendencia estadística sobre la media del nivel de las competencias digitales incorporadas por los docentes, en el nivel de dominio Avanzado tiene una media de 8,0 \%; Intermedio 16,6 \%; Medio 19,0 \%; Básico 27,9 \% y Nulo 28,5 \%. La media que tiene mayor frecuencia sobre el nivel de dominio de las competencias digitales, tiene mayor representatividad el nivel Básico, que tiene una tendencia de $27 \%$.

En la pregunta 33 sobre el nivel de apropiación de las competencias digitales en el Área de Información y alfabetización digital mediante una escala de Likert, los resultados son los siguientes:

\begin{tabular}{|c|c|c|c|c|c|c|}
\hline \multicolumn{2}{|c|}{$\begin{array}{l}\text { Pregunta 33: Nivel de apropiación de las } \\
\text { competencias digitales que usted } \\
\text { considera que domina en los siguientes } \\
\text { ítems }\end{array}$} & \multirow{2}{*}{$\begin{array}{c}\begin{array}{c}\text { Avanzado } \\
\text { \% }\end{array} \\
\\
25,7\end{array}$} & \multirow{2}{*}{$\begin{array}{c}\begin{array}{c}\text { Intermedio } \\
\%\end{array} \\
\\
36,7\end{array}$} & \multirow{2}{*}{$\begin{array}{l}\begin{array}{l}\text { Medio } \\
\text { \% }\end{array} \\
20,2 \\
\end{array}$} & \multirow{2}{*}{$\begin{array}{l}\begin{array}{l}\text { Básico } \\
\%\end{array} \\
13,8\end{array}$} & \multirow{2}{*}{$\begin{array}{l}\begin{array}{l}\text { Nulo } \\
\%\end{array} \\
3,7 \\
\end{array}$} \\
\hline 1 & $\begin{array}{l}\text { Uso de procesador de texto (ej. } \\
\text { Word) }\end{array}$ & & & & & \\
\hline 2 & $\begin{array}{l}\text { Uso de procesador de } \\
\text { presentaciones (ej. Power Point) }\end{array}$ & 21,1 & 42,2 & 20,2 & 11,9 & 4,6 \\
\hline 3 & Uso de hojas de cálculo (ej. Excel) & 13,8 & 33,0 & 23,9 & 21,1 & 8,3 \\
\hline 4 & $\begin{array}{l}\text { Uso de programas de análisis } \\
\text { estadístico (ej. SPSS) }\end{array}$ & 5,5 & 14,7 & 11,0 & 33,9 & 34,9 \\
\hline 5 & $\begin{array}{l}\text { Uso en Microsoft Office } 365 \text { la } \\
\text { aplicación Teams para tomar crear } \\
\text { equipos y realizar videollamadas }\end{array}$ & 9,2 & 22,0 & 23,9 & 33,9 & 11,0 \\
\hline 6 & $\begin{array}{l}\text { Uso en Microsoft Office } 365 \text { la } \\
\text { aplicación Forms para crear } \\
\text { cuestionarios o formularios }\end{array}$ & 6,4 & 19,3 & 22,0 & 36,7 & 15,6 \\
\hline 7 & $\begin{array}{l}\text { Uso en Microsoft Office } 365 \text { la } \\
\text { aplicación SharePoint para crear } \\
\text { trabajos en equipos y gestión } \\
\text { documental }\end{array}$ & 2,8 & 17,4 & 15,6 & 23,9 & 40,4 \\
\hline 8 & $\begin{array}{l}\text { Uso en Microsoft Office } 365 \text { la } \\
\text { aplicación OneNote para tomar } \\
\text { anotaciones y recopilar información }\end{array}$ & 4,6 & 14,7 & 16,5 & 24,8 & 39,4 \\
\hline 9 & $\begin{array}{l}\text { Uso en Microsoft Office } 365 \text { la } \\
\text { aplicación Outlook para enviar y } \\
\text { recibir correos electrónicos }\end{array}$ & 11,9 & 27,5 & 25,7 & 22,9 & 11,9 \\
\hline
\end{tabular}




\begin{tabular}{lllllll}
\hline 10 & $\begin{array}{l}\text { Uso en Microsoft Office 365 la } \\
\text { aplicación OneDrive para alojar } \\
\text { información en la nube }\end{array}$ & 6,4 & 18,3 & 15,6 & 33,0 & 26,6 \\
\hline
\end{tabular}

Cuadro 8. Nivel de habilidades que usted considera que domina

Entre el nivel de apropiación de las competencias, según la escala, se evidencia que los docentes tienen mayor porcentaje de apropiación en los ítems 1, 5 y 6 . Además, el nivel de apropiación nulo tiene mayor porcentaje en los ítems 3, 4 y 7. El nivel de apropiación Intermedio, con mayores datos porcentuales, se encuentra en el ítem 2, 8, 9 y 10.

\subsection{Capital tecnológico institucionalizado}

El espacio de la encuesta para poder conocer sobre el capital tecnológico institucionalizado de los docentes se estableció desde la pregunta 34 hasta la 38.

En la pregunta 34, que se preguntó sobre el nivel de habilidades en el manejo de herramientas ofimáticas y de Microsoft Office 365, los resultados obtenidos fueron los siguientes:

En la pregunta 34, ¿antes de la pandemia de la Covid-19, en su institución educativa recibió capacitaciones sobre el uso de herramientas tecnológicas? Los ítems de respuesta fueron sí y no; con un 31 \% respondieron que Sí y el 69 \% respondió que No. En la pregunta 35 sobre ¿Usted antes de la pandemia de la Covid-19 había utilizado plataformas como: Zoom, Teams o Moodle? Respondieron Sí el 69 \% y el 31 \% No.

En la pregunta 36, ¿Tiene algún tipo de certificado o título académico sobre competencias digitales del uso de TIC o manejo de herramientas informáticas?, los docentes respondieron $55 \%$ No y un $45 \%$ que Sí.

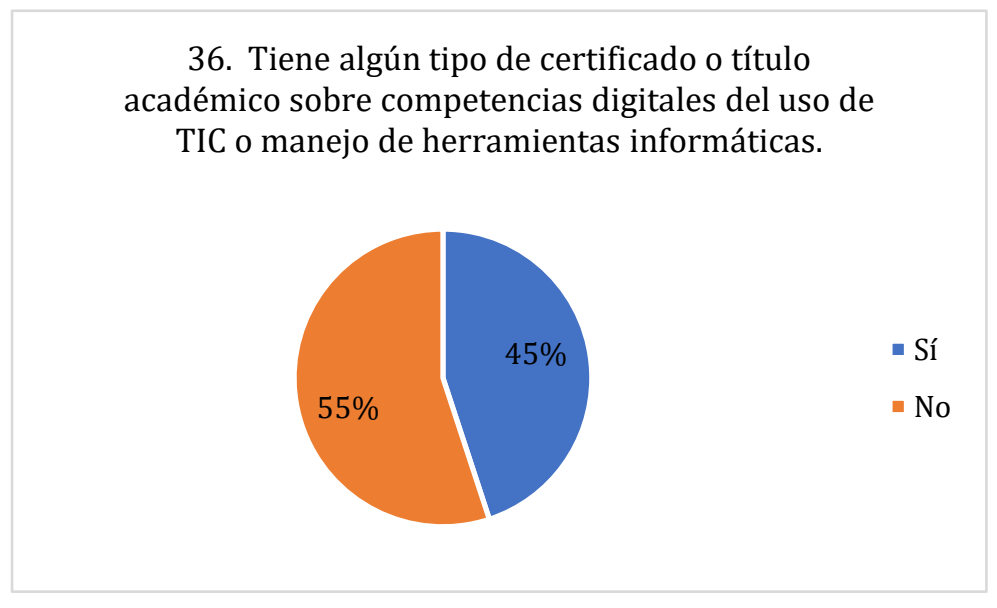

Figura 1. Tiene algún tipo de certificado o título académico sobre el uso de TIC

La pregunta 37 y 38 tienen relación entre sí. La pregunta 37 ¿Usted durante los últimos 6 meses ha recibido alguna capacitación sobre competencias tecnológicas del uso de herramientas tecnológicas?, respondieron el 72 \% Sí y el 28 \% No. A continuación, en la pregunta 38 solo debían responder quienes en la pregunta 37 seleccionó la opción Sí, y seleccionar de qué tipo fue su capacitación, un total de 65 docentes mencionó que fueron gratuitos, 18 docentes que fueron cursos pagados, y 5 docentes que fueron cursos cofinanciados. 


\section{Discusión de los resultados}

Todos los docentes encuestados poseen una determinada forma de capital tecnológico objetivado, que se expresa mayoritariamente en computadora de escritorio, laptop, impresora con escáner, smartphone y radio. Por ejemplo, de los 109 encuestados, 103 docentes respondieron que tienen una laptop, 63 docentes tienen impresora con escáner y 59 docentes tienen radio. Sin embargo, esto está determinado por su situación socio económica. Así, por ejemplo, en la pregunta 21 que establece: ¿El equipo tecnológico que usted usa para impartir sus clases en línea fue proporcionado por la institución educativa donde labora? Al respecto el $57 \%$ de encuestados respondió de manera afirmativa, mientras que el $43 \%$ respondió de manera negativa. Podemos inferir que ha existido un limitado apoyo del Ministerio de Educación hacia los docentes, aun cuando la Organización de las Naciones Unidas ha exhortado a los Estados, manifestando que "los docentes y los estudiantes necesitan tecnologías gratuitas y de código abierto para la enseñanza y el aprendizaje" (ONU, 2020, pág.27).

El aspecto de Comprensión del papel de las TIC en las políticas educativas de las competencias digitales establecidas por la UNESCO, orienta a que las prácticas docentes guarden armonía con las políticas educativas. Al respecto en la pregunta 11 del instrumento se indagó; ¿Cuánto tiempo emplea para impartir clases a sus estudiantes mediante el uso de las plataformas digitales? El $48 \%$ de encuestados respondió que emplea de 4 a 6 horas, el $39 \% 40$ minutos y el $13 \% 1$ hora. Esto evidencia que solo la actividad docente del $52 \%$ de encuestados guarda concordancia con el Plan Educativo "aprendemos juntos en casa" donde se regula el tiempo de trabajo, estableciendo las siguientes pautas "(120) ciento veinte minutos para actividades académicas y (30) treinta minutos para tareas o refuerzo, para estudiantes de EGB superior; 16 años: dos horas" (MINEDUC, 2020, pág. 19).

El aspecto pedagógico y curricular del Capital Tecnológico incorporado, está orientado a que "los docentes integran tecnologías, herramientas y contenidos digitales para potenciar la enseñanza" (pág. 29). Así, por ejemplo, en la pregunta 15 se interrogó; ¿Qué tipos de plataformas educativas usa usted para asignar las tareas a sus estudiantes? El $39 \%$ de encuestados usa Google Classroom, el 22 \% usa Moodle, el $19 \%$ el Paquete de Microsoft Office 365 , el $15 \%$ usa la plataforma propia de la institución y el $6 \%$ usa Edmodo. Asimismo, en la pregunta 16 se interrogó; ¿Qué tipos de plataformas educativas usa usted para aplicar las evaluaciones a sus estudiantes? El $35 \%$ de encuestados usa Google Classroom, el $22 \%$ usa Moodle, el $20 \%$ usa la plataforma propia de la institución, el $17 \%$ usa el paquete de Microsoft Office 365 y $6 \%$ usa Edmodo. De las preguntas comparadas se puede observar una desviación estándar del $11 \%$, que demuestra una dispersión o variabilidad entre las respuestas de los encuestados. Podemos inferir que los docentes no utilizan las plataformas digitales de manera mecánica, por el contrario, lo hacen en función de las necesidades que demandan ciertas actividades educativas; como evaluación y asignación de tareas.

Al respecto de la aplicación del Capital Tecnológico incorporado donde "los docentes utilizan ordenadores, dispositivos móviles, programas informáticos accesibles, y redes, con fines de enseñanza, aprendizaje y gestión (...)" (UNESCO, 2019, pág. 30). Los docentes encuestados, en la pregunta 31 en el ítem 17 que interrogó sobre el uso de correo electrónico respondió que el 22,9 \% de encuestados tiene un nivel Avanzado, el 26,6 \% Intermedio, el 13,8 \% Medio, el 22,9 \% Básico y el 13,8 \% Nulo. Asimismo, en el ítem 7 de la pregunta 32 que interroga sobre el diseño de presentaciones interactivas, el 9,2\% de encuestados tiene un nivel Avanzado, el 17,4 \% Intermedio, el 26,6 \% Medio, el 33,9 \% Básico y el 12,8 \% Nulo. Además, en la pregunta 33 ítem 1 que se refiere al Uso de un procesador de texto para crear documentos, el 25,7 \% de docentes tiene un nivel Avanzado, el 36,7\% Intermedio, el 20,2 \% Medio, el 13,8 \% Básico y el 3,7 \% Nulo. Según el análisis 
estadístico descriptivo de las tres preguntas en correspondencia a un total de 45 ítems, la media del nivel de incorporación de estas competencias digitales corresponde a 11,1\% Avanzado, 20,4 \% Intermedio, 21,8 \% Medio, 27,1 \% Básico y un 13,1 \% Nulo. Por lo tanto, de los datos discutidos podemos afirmar que la mayor parte de docentes tiene un nivel Medio en cuanto al manejo y uso de capital tecnológico incorporado.

En referencia al Capital Tecnológico en su estado institucionalizado, entendido como todo ese conjunto de elementos que recubren de valor simbólico del conocimiento adquirido. En la pregunta 36 que interrogó; ¿Tiene algún tipo de certificado o título académico sobre competencias digitales del uso de TIC o manejo de herramientas informáticas? El $55 \%$ de docentes respondió No y el 45 \% restante, respondió Sí. Asimismo, en la pregunta 37 que indagó; ¿Durante los últimos 6 meses ha recibido alguna capacitación sobre competencias tecnológicas del uso de herramientas tecnológicas? El 72 \% de docentes respondieron Sí y el $28 \%$ restante No. De lo cual podemos deducir que a pesar del dominio de las competencias digitales no existe correspondencia con los certificados y diplomas que acrediten su capital tecnológico incorporado.

\section{Conclusiones}

Los docentes poseen Capital Tecnológico. En su estado objetivado poseen en mayor medida las siguientes formas de KT; computadora de escritorio, laptop, smartphone, televisión inteligente, impresora con escáner y radio. Sin embargo, cabe anotar que la mayoría de estos instrumentos han sido adquiridos por autofinanciamiento del docente. En su estado incorporado, tienen un nivel Medio de apropiación de KT, que les permite desarrollar y aplicar las seis competencias en TIC, en materia de educación, para fortalecer el proceso de enseñanza. En su estado institucionalizado, más de la mitad de los docentes han participado en cursos de capacitación, obteniendo un certificado que acredite su conocimiento incorporado. Sin embargo, los procesos de capacitación aumentaron producto de las exigencias provocadas por la pandemia. Antes de la pandemia los niveles de capacitación eran menores.

Organismos internacionales como ONU, UNICEF, CEPAL y UNESCO, han exhortado a los Estados a proteger e incrementar la inversión pública en educación para garantizar el ejercicio de este derecho durante la pandemia. Además, por mandato constitucional, el Estado ecuatoriano a través del Ministerio de Educación está en la obligación de generar las políticas y servicios públicos que garanticen una educación de calidad, entre esas políticas públicas se encuentra; la ampliación del capital tecnológico de los docentes con perspectiva de aplicar las competencias en TIC de forma crítica, reflexiva y dinámica.

No existen antecedentes en el país sobre estudios específicos de Capital Tecnológico aplicado en la educación, por lo tanto, esta investigación se constituye en un eje de discusión sobre el Capital Tecnológico, su apropiación, aplicación e influencia en el proceso de enseñanza-aprendizaje. Finalmente, se espera realizar a mediano plazo, un nuevo estudio sobre la apropiación de capital tecnológico de los docentes en instituciones educativas ubicadas en cantones y/o parroquias rurales, donde se pueda comparar los datos presentados en esta investigación con nuevos resultados, para visibilizar a posteriori el desarrollo, niveles y formas de apropiación de capital tecnológico: objetivado, institucionalizado e incorporado.

\section{Agradecimientos}

Extendemos nuestro agradecimiento a las autoridades de las Instituciones educativas que nos brindaron las facilidades para la recolección de información. Un agradecimiento 
especial a la MSc. Irene Tituaña Rectora de la Unidad Educativa Abdón Calderón, quien fue el nexo y apoyo en la elaboración de este estudio. 


\section{Bibliografía}

Botello, H., y Guerrero, A. (2014). La influencia de las TIC en el desempeño académico de los estudiantes en América Latina: Evidencia de la prueba PISA 2012. Revista Academia y Virtualidad, 7(2), 15-26.

Bourdieu, P. (2001). Language and Symbolic Power (Tercera edición). Cambridge: Polity Press.

Bourdieu, P. (2003). Los Herederos: Los estudiantes y la cultura (Segunda edición). México: Siglo veintiuno editores. Recuperado el 7 de febrero de 2021, de https://bit.ly/3sMsSx0

Bourdieu, P. (2012). Los Tres Estados del Capital Cultural. Sociológica, (5), 11-17.

Casillas-Alvarado, M., Ramírez-Martinell, A., y Ortíz-Méndez, V. (2013). El Capital Tecnológico una nueva especie del Capital Cultural. Una propuesta para su medición. [Memorias del Congreso]. XII Congreso Nacional de Investigación Educativa, Guanajuato. Recuperado el 10 de febrero de 2021, de https://bit.ly/3sLXKxT

Castells, M. (2009). Comunicación y Poder (Primera edición). Recuperado el 8 de febrero de 2021, de https://bit.ly/3ayb8zi

CEPAL-UNESCO. (2020). La educación en tiempos de la pandemia de COVID-19 (pp. 1-21) [Informe Covid-19]. CEPAL-UNESCO. Recuperado el 8 de febrero de 2021, de https://bit.ly/3tK3fhz

Han, B.-C. (2014). Psicopolítica: Neoliberalismo y nuevas técnicas de poder (Primera edición). Barcelona: Herder.

Instituto Nacional de Estadísticas y Censos. (2019). Tecnología de la Información y Comunicación (Encuesta Nacional Multipropósito de Hogares, pp. 1-41) [Estadístico]. INEC.

Krüger, K. (2006). El concepto de sociedad del conocimiento. Revista Bibliográfica de Geografía y Ciencias Sociales, XI (683). Recuperado el 7 de enero de 2021, de https://bit.ly/3dIHwBl

Mendoza, L. (2020). Lo que la pandemia nos enseñó sobre la educación a distancia. Revista Latinoamericana de Estudios Educativos, L (Especial), 343-352.

MINEDUC. (2020). Plan Educativo Aprendamos Juntos en Casa (pp. 1-31) [Lineamientos Ámbito Pedagógico Curricular]. Ministerio de Educación de Ecuador.

OREALC/UNESCO. (2013). Enfoques estratégicos sobre las TICS en Educación en América Latina y el Caribe. Oficina Regional de Educación para América Latina y el Caribe. [Enfoques estratégico]. Recuperado el 10 de febrero de 2021, de https://bit.ly/2R04lHv

Organización de las Naciones Unidas. (2020). Informe de políticas: La educación durante la COVID-19 y después de ella (pp. 1-29) [Orientaciones educativas]. ONU.

Organización de las Naciones Unidas para la Educación, la Ciencia y la Cultura. (2017). Sociedad digital: Brechas y retos para la inclusión digital en América Latina y el Caribe (Educación N. ${ }^{\circ}$ 7; pp. 1-23). UNESCO. Recuperado el 8 de febrero de 2021, de https://bit.ly/3dGNTF2 
Organización de las Naciones Unidas, para la Educación, y Organización de las Naciones Unidas para la Educación, la Ciencia y la Cultura. (2019). Marco de competencias de los docentes en materia de TIC UNESCO (Orientaciones educativas N.o 3; pp. 1-64). UNESCO.

Pérez, Á. (2013). La era digital. Nuevos desafíos educativos. En Educarse en la era digital (Primera edición). Ediciones Morata. Recuperado el 8 de febrero de 2021, de https://bit.ly/3tSajsN

Ramírez-Martinell, A., y Casillas Alvarado, M. (2014). El capital tecnológico una nueva especie del capital cultural: Una propuesta para su medición. En Háblame de TIC (Primera edición, pp. 1-23). Córdoba: Brujas.

Taber, K. (2017). The Use of Cronbach's AlphaWhen Developing and Reporting Research Instruments in Science Education. Springer, 1273-1296.

Salado- Rodríguez, L., Velázquez- García, M., y Ochoa- Landín, R. (2014, noviembre 12). El capital tecnológico y el ejercicio docente: El caso de la Universidad Estatal de Sonora [Congreso]. Congreso Iberoamericano de Ciencia, Tecnología, Innovación y Educación, Buenos Aires.

Salado-Rodríguez, L., y Ramírez-Martinell, A. (2018). Capital cultural en el contexto tecnológico: Consideraciones para su medición en la educación superior. Revista Iberoamericana de Educación Superior, IX (24), 125-137.

Uzcátegui, K., y Albarrán, J. (2020). Desafíos y dificultades de los docentes de educación primaria ante la adopción de la tele-educación. Revista Andina de Educación, 4 (1), 43-54.

Vein, C. (2013). Conectarse para trabajar: Cómo las TIC amplían las oportunidades de empleo en todo el mundo [Noticias]. Banco Mundial. Recuperado el 7 de febrero de 2021, de https://bit.ly/3sKrRFC 


\section{Autores}

LIZBETH PONCE-TITUAÑA obtuvo su título de Licenciada en Ciencias de la Educación mención Ciencias Sociales en la Universidad Central del Ecuador (Ecuador) en 2019. Obtuvo el título de Especialista Superior en Educación y Nuevas Tecnologías de la Información y Comunicación por la Universidad Andina Simón Bolívar (Ecuador) en 2020. Obtuvo el reconocimiento de la mejor estudiante de su promoción en la Especialización Superior en Educación y Nuevas Tecnologías de la Información y Comunicación por la Universidad Andina Simón Bolívar (Ecuador) en 2021.

Actualmente es estudiante en la Maestría de Investigación en Educación de la Universidad Andina Simón Bolívar (Ecuador) 2020.

ALEX LUCIO-PAREDES se graduó de Licenciado en Ciencias de la Educación mención Ciencias Sociales de la Universidad Central del Ecuador (Ecuador) en 2019. Estudiante de la Universidad Andina Simón Bolívar (Ecuador) 2021.

Actualmente es estudiante de la Carrera de Derecho, de la Facultad de Jurisprudencia, Ciencias Políticas y Sociales, en la Universidad Central del Ecuador (Ecuador). 